\title{
Seismograms Explained by the Slip Distribution of the 1995 Hyogo-ken Nanbu Earthquake
}

\author{
Kiyoshi Yomogida ${ }^{1, *}$ and Takashi Nakata ${ }^{2}$ \\ ${ }^{1}$ Department of Earth and Planetary Systems Science, Faculty of Science, \\ University of Hiroshima, Higashi-Hiroshima 739, Japan \\ ${ }^{2}$ Department of Geography, Faculty of Letters, University of Hiroshima, \\ Higashi-Hiroshima 739, Japan
}

One of the most striking features of the 1995 Hyogo-ken Nanbu earthquake was the appearance of clear surface faultings of over $9 \mathrm{~km}$ on Awaji Island. There are still numerous speculations on the location and characteristics of faultings in Kobe, the northeastern part of the entire fault system, because no surface faultings of large scale have ever been reported (e.g., Tsukuda, 1996). In contrast, the location of the fault plane on Awaji Island, the southwestern part of the fault system, was identified with no doubt. Clear right-lateral slips were observed on the surface along the Nojima fault, to the northwest of Awaji Island (Nakata et al., 1995; Nakata and Yomogida, 1995). Since this earthquake provided a great opportunity to study detailed characteristics of surface faultings associated with a great in-land earthquake, it is important to investigate how the surveyed fault characteristics on the surface are related to some geophysical, particularly seismological, observations. For example, the aftershock distribution was found to agree grossly with the location of the surface faultings on Awaji Island, suggesting a nearly vertical fault plane. This nearly vertical fault plane was confirmed by a recent deep borehole trench across the Nojima fault conducted by the Geological Survey of Japan ( $\mathrm{H}$. Itoh, personal communication). The location of subevents retrieved by teleseismic studies such as Kikuchi (1995) is also consistent with our studies on the surface breaks, as well as strong-motion studies (e.g., Sekiguchi et al., 1996; Kamae and Irikura, 1995).

Yomogida and Nakata (1995) discussed several relations of field-surveyed fault characteristics with

Received November 16, 1995; Accepted June 13, 1997

* To whom correspondence should be addressed. seismic data. One of the most striking results was that some broadband seismograms may be closely related with the slip distribution observed along the Nojima fault, down to the scale of $1 \mathrm{~km}$. Since broadband seismograms should be strongly affected by propagation effect, with a minimum site effect because of the borehole setting, a realistic earth structure and a double-couple source must be considered in the above discussion. This study focuses on how the fine-scale slip distribution observed on the surface can explain broadband seismic observations quantitatively.

Figure 1 shows the location of fault traces along the Nojima fault and the slip distribution along the surface breaks. No systematic patterns of verticalslip component were found and the surface faultings can be described well as pure right-lateral slip. The amount of lateral slip is not nearly constant along the Nojima fault but the spatial slip distribution can be seen in a wide range of scales. In a large scale, the present fault system can be expressed by five segments, as shown in Fig. 1. The length of each segment is about $2 \mathrm{~km}$, and the amount of lateral slip is maximum in the mid-section of each segment and goes to zero at both ends. As described in Nakata et al. (1995), spatial variations of slip can be observed on a scale down to meters. Surface faultings are characterized not by a simple straight line, but have complex structures such as jogs, branches and en-echelons. They are more likely described as fractal (e.g., Okubo and Aki, 1984; Matsumoto et al., 1992). The fractal structures of surface faultings should be related to high-frequency seismic-wave radiation because a smooth rupture 

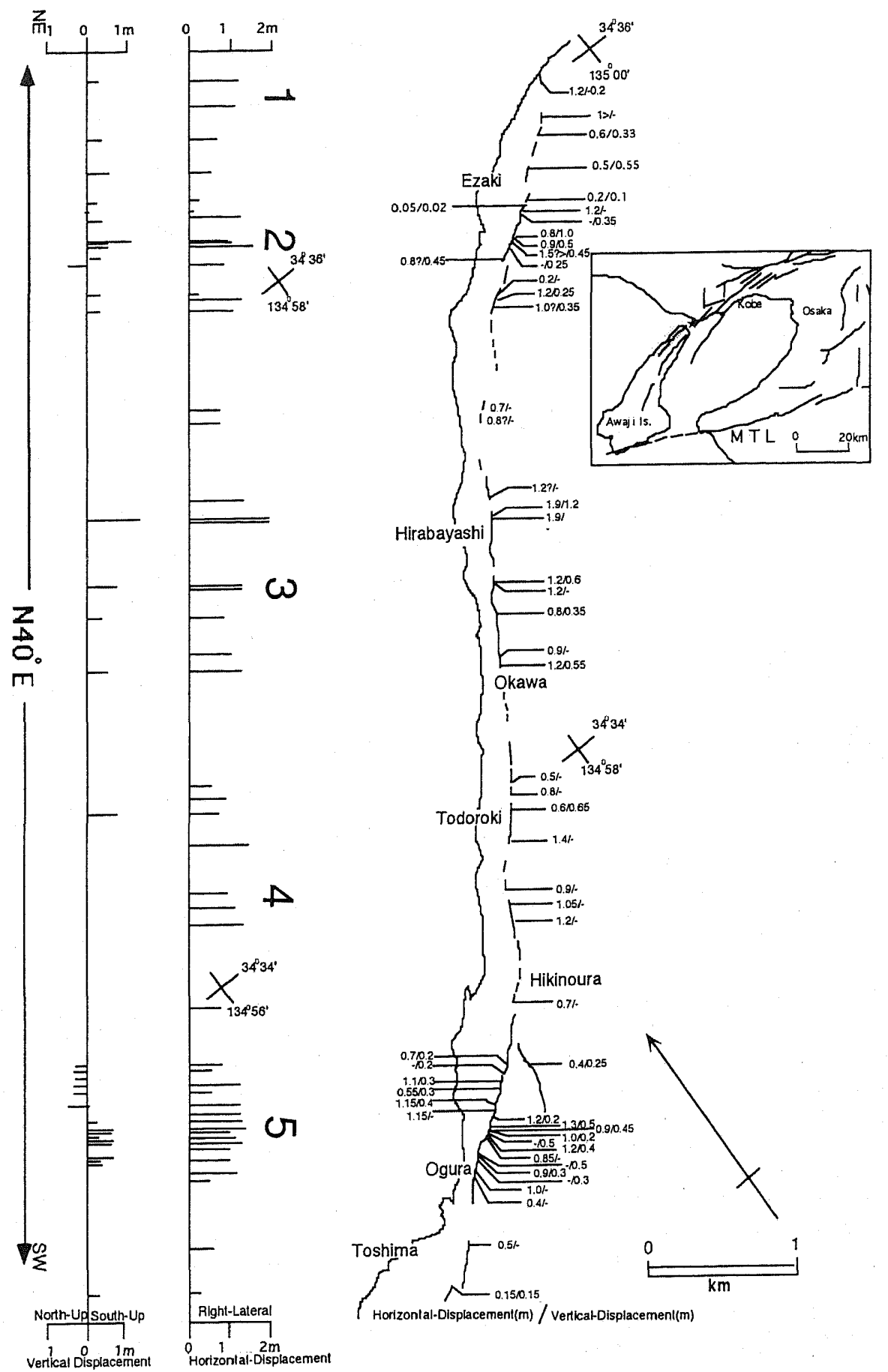

Fig. 1. Fault trace map and the amount of vertical and horizontal slips along the Nojima fault on Awaji Island. Revised from Nakata and Yomogida (1995). 
propagation, forming one straight crack, radiates much less high-frequency seismic waves than normally observed (e.g., Aki and Richards, 1980). The relation between the fractal structure of the observed fault trace and high-frequency seismicwave radiation will be discussed in a stochastic manner, but in this study we consider only the largest-scale spatial variation of the faultings along the Nojima fault (i.e., five segments in Fig. 1) using a deterministic approach.

To relate the above spatial slip variation to seismic observations, we should study seismic waves of frequency about 1 to $4 \mathrm{~Hz}$ because the considered fault segmentation is at the scale of the order of $1 \mathrm{~km}$. We therefore use not teleseismic data but seismograms not far from the fault, although site and/or path effects are not totally negligible for them. Strong-motion records near the fault system are the best to retrieve detailed source processes. All the reported strong-motion records, however, seem to be affected by their geological surface conditions (e.g., Iwata et al., 1995). Broadband seismograms
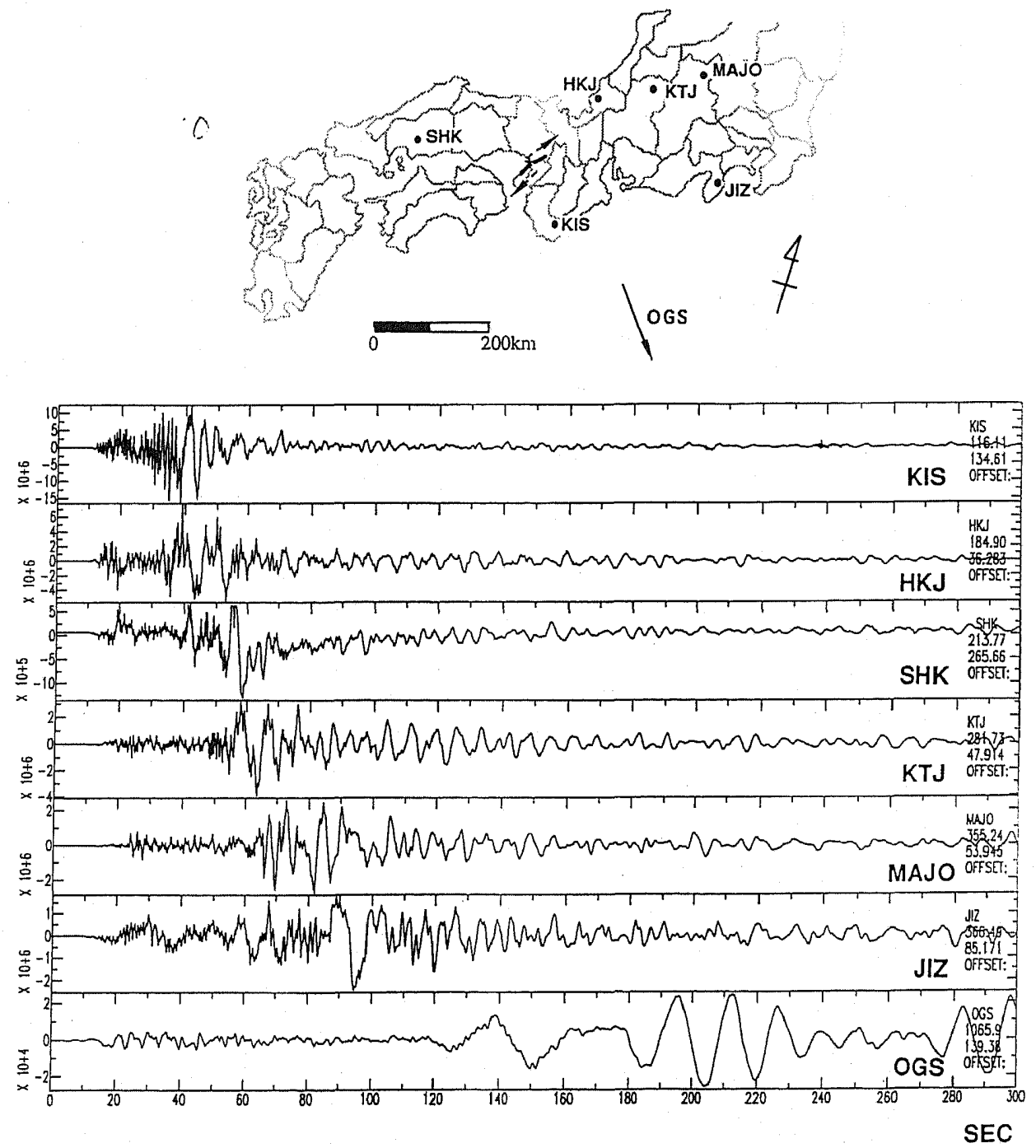

Fig. 2. Vertical component of broadband velocity seismograms in Japan and their locations. The initial phase is set at $10 \mathrm{~s}$ for each record. Reproduced from Yomogida and Nakata (1995).

Vol. 45, No. 2, 1997 
recorded in Japan are selected in this study because they are of relatively high quality, have good signal-to-noise ratio and appear to be affected little by site effects.

Figure 2 shows broadband vertical velocity seismograms recorded in Japan. In this figure, seismograms are plotted with the epicentral distance increasing from the top (KIS) to the bottom (OGS). High-frequency waves (over $1 \mathrm{~Hz}$ ) clearly decrease as the epicentral distance increases, suggesting that the high-frequency waves in these records are mainly radiated for the source complexity, related with the fault characteristics. We use only the early part of the $\mathrm{P}$ wave in the vertical component (Fig. 3).

Although the early part of the $\mathrm{P}$ wave is affected the least by propagation effects, seismograms at epicentral distances from 100 to $400 \mathrm{~km}$ should be treated carefully. In this epicentral range, even a one-dimensional earth structure produces significant complexities in seismograms. For example, due to the sharp increase in velocity at the Moho, the interface between the crust and the upper mantle, a kind of head wave is noticeable in records, often called $P_{n}$, arriving earlier than the direct $P$ wave (e.g., Helmberger, 1983). Another important factor is the radiation patterns of $\mathrm{P}$ and $\mathrm{S}$ waves. Because some stations are close to a node of radiation patterns, we must avoid those stations. In this study, we compare observed records with synthetic seismograms for a one-dimensional earth model and a double-couple point source. It might be necessary to include the effects of lateral heterogeneities and complex rupture processes on a finite fault plane. Nevertheless, the above two factors are the most critical for the purpose of this study.

We use the reflectivity method of Kennett (1988) to obtain synthetic seismograms so that we can consider all the multiple reflected and transmitted waves, including $P_{n}$, a kind of head wave. The earth structure model is the flat one used in Kennett (1988), derived from the model SNA (Grand and Helmberger, 1984), as shown in Fig. 4. Although velocity structure should be very sensitive to detailed waveforms of synthetic seismograms, our main conclusions in this study are proved to stand after several tests with different velocity structures.

The adopted double-couple solution is taken from the CMT inversion solution by Cho et al. (1995). Their best double-couple solution is as follows: $M_{r r}=-0.067, M_{\theta \theta}=0.261, M_{\phi \phi}=-0.277, M_{r \theta}=$

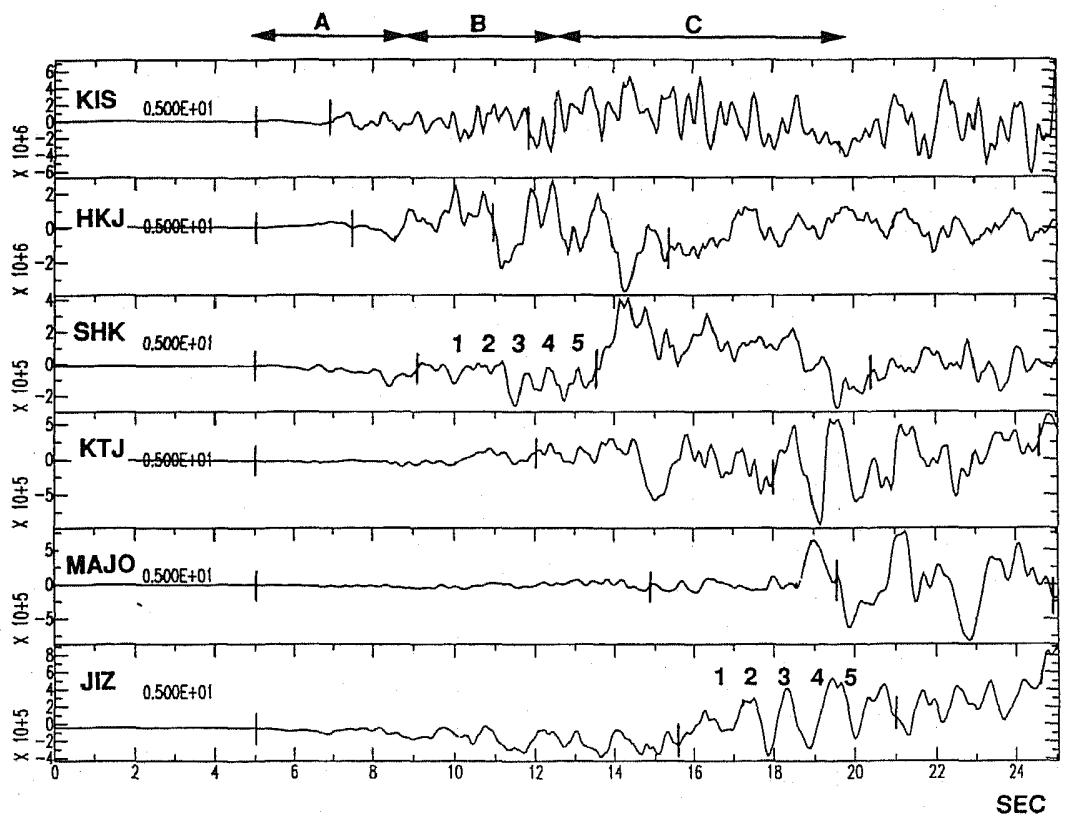

Fig. 3. Details of early part of $P$ waves shown in Fig. 2, except for OGS, with the initial phase set at $5 \mathrm{~s}$. Most of the records can be divided into three parts (A, B, and $C$ ), with five pulses in $B$. Reproduced from Yomogida and Nakata (1995). 


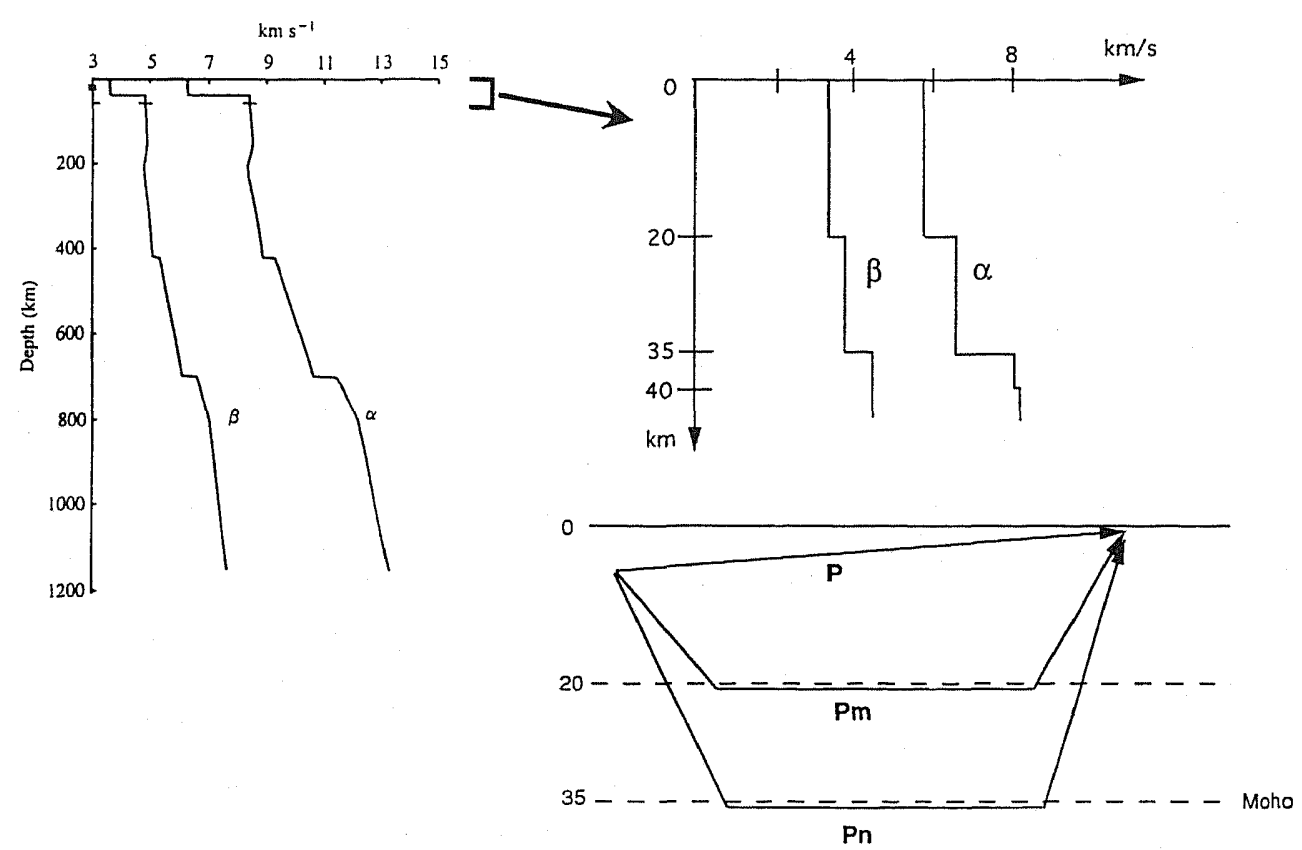

Fig. 4. Velocity structure model based on the model SNA (Grand and Helmberger, 1984) and ray paths of three major P-related phases $\left(P, P_{m}\right.$, and $\left.P_{n}\right)$ in this study.

$-0.067, M_{r \phi}=0.016$, and $M_{\theta \phi}=-0.087$, in units of $10^{20} \mathrm{~N} \cdot \mathrm{m}$. The total seismic moment is $2.9 \times 10^{19}$ $\mathrm{N} \cdot \mathrm{m}$, and the slip is nearly pure right-lateral with a strike of $233 \mathrm{deg}$ or N53E. The focal depth cannot be well resolved for shallow earthquakes such as the present event. From the aftershock distribution (e.g., D.P.R.I. R.C.E.P., 1995), coseismic fault motions appear to have extended from the surface to a depth of 10 to $15 \mathrm{~km}$. We set the point source at the depth of $5 \mathrm{~km}$ to represent the centroid of fault slips.

In order to understand the effects of the crustupper mantle structure and the radiation pattern, we make synthetic seismograms at various epicentral distances in each azimuth of Fig. 3. Figure 5 shows two examples of synthetic vertical velocity seismograms with an impulsive source-time function in azimuths of (a) SHK and (b) MAJO, respectively. They are bandpassed between 0.1 and $3 \mathrm{~Hz}$. Each trace is aligned with the reduced travel time of the P-wave velocity at the uppermost mantle $(8.11 \mathrm{~km} / \mathrm{s})$. Figure 5 clearly shows that the early part of the $\mathrm{P}$ wave consists mainly of three distinct phases in the epicentral distance over $150 \mathrm{~km}$ : a first small phase, followed by a minor one and a third major phase. The slowness of the first phase is
$(8.11 \mathrm{~km} / \mathrm{s})^{-1}$, suggesting that it is a kind of head wave propagating just beneath the Moho, as denoted by $P_{n}$ in Fig. 4. Our model has a slight jump in velocity in the middle of the crust, as shown in Fig. 4 , resulting in a weaker head-wave type phase propagating beneath this interface, similar to $P_{n}$. The second phase in Fig. 5 corresponds to this type of head wave, as represented by $\mathrm{P}_{\mathrm{m}}$ in Fig. 4. These head-wave type phases have more low frequencies than direct phases, which are not suitable to estimate detailed rupture processes (e.g., Aki and Richards, 1980; Helmberger, 1983).

The final large phase in the P-wave part is the direct $\mathrm{P}$ wave. For our purposes, we concentrate ourselves on this phase. In other words, we select seismograms in which the direct $P$ wave can be clearly identified. In the epicentral distance of less than $200 \mathrm{~km}$, the above three phases arrive nearly simultaneously so that the waveform is quite complex, even for the impulsive source-time function. The radiation pattern, due to the doublecouple source mechanism, is also important to find such suitable stations. In the azimuth of SHK (Fig. 5(a)), for example, the direct $\mathrm{P}$ wave is relatively clear because it is in a direction close to the maximum 

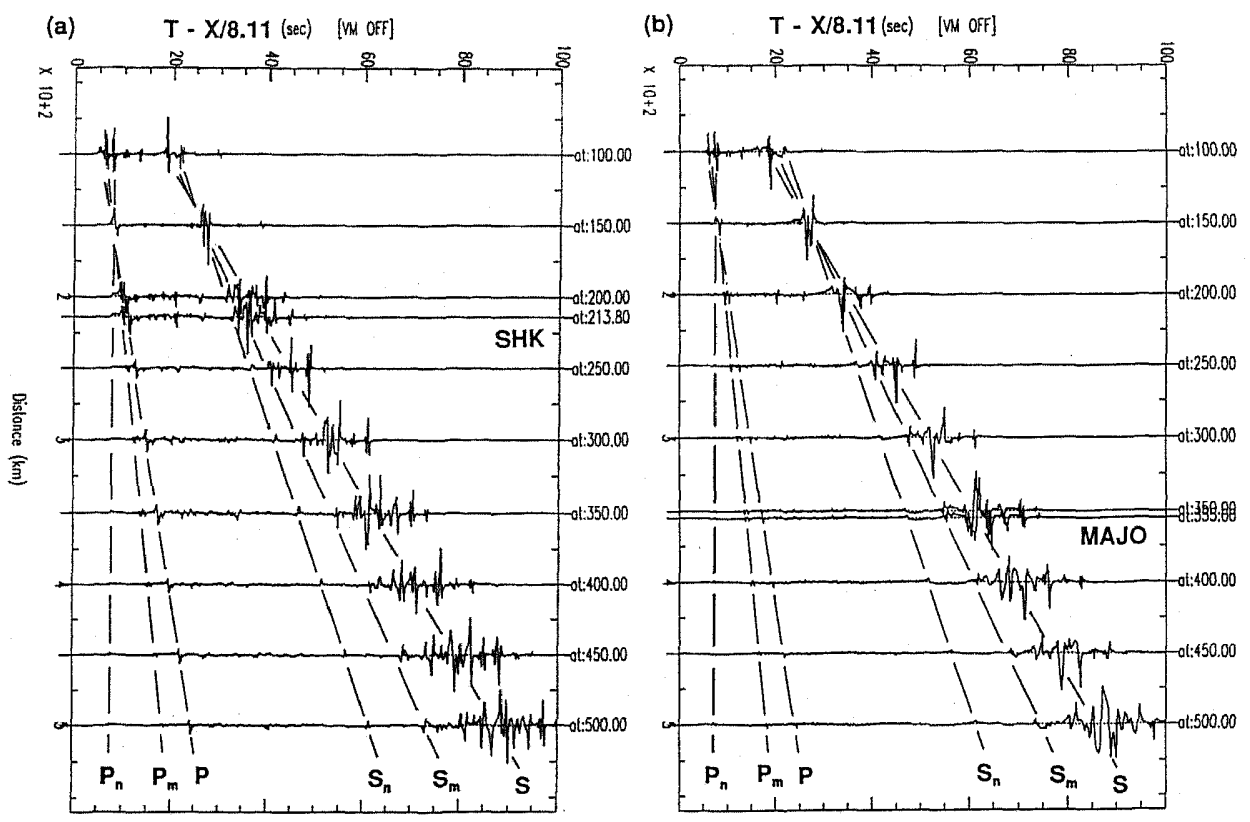

Fig. 5. Synthetic seismograms of vertical component at various distances in the azimuths of (a) SHK and (b) MAJO, respectively. Double-couple point source of Cho et al. (1995) is used with an impulse source-time function. The seismograms are filtered between 0.1 and $3 \mathrm{~Hz}$.

of the P-wave radiation. In contrast, all three P-related phases are very weak in the azimuth of MAJO (Fig. 5(b)), particularly the direct $P$ wave, because the azimuth is close to a node of the P-wave radiation, while $S$-related phases are rather strong. $\mathrm{S}$-to-P wave conversions at interfaces along the path contaminate the $\mathrm{P}$-wave part, resulting in inappropriate seismograms.

Figure 6 shows synthetic seismograms of vertical $P$ wave with the impulsive source-time function at each station in Fig. 3. The first arrival at each synthetic seismogram is set at $5 \mathrm{~s}$. The direct $P$ wave arrives first at KIS, whose epicentral distance is less than $150 \mathrm{~km}$, while $P_{n}$, a head-wave type phase propagating beneath the Moho (Fig. 4), arrives first at other stations of larger epicentral distances. The three P-related phases $\left(P, P_{m}\right.$, and $\left.P_{n}\right)$ arrive simultaneously at $\mathrm{HKJ}$, from which it is difficult to retrieve the source process. Due to the radiation pattern, the direct $P$ wave is very small relative to the other phases at stations such as KIS, KTJ, and MAJO, while the direct $\mathrm{P}$ wave is isolated and of large amplitude at SHK and JIZ. Although waveforms show some complexities by other phases such as $P_{n}$ and $P_{m}$, we can discuss detailed source processes by identifying the direct $\mathrm{P}$-wave phase at these two stations.

We next make synthetic seismograms for the source process estimated from the slip distribution (Fig. 1) and compare them with the broadband seismic observations (Fig. 3). As discussed in Yomogida and Nakata (1995), one major assumption in this study is that the fault characteristics observed on the surface do not differ significantly from the entire fault plane down to a depth of 10 or $15 \mathrm{~km}$. This assumption may be questioned as follows: since physical properties are strongly varied in depth, complexities in faulting might be very different between the surface and deep in the crust. We cannot exclude such possibility completely, but the similarity between the synthetic and observed seismograms under the above assumption, as shown in the end, appear to support it. Another evidence comes from a deep borehole survey that crossed the Nojima fault at the depth of more than $500 \mathrm{~m}$ in Hirabayashi, where the fault slip is maximum. The earthquake fault is nearly vertical and the apparent nature of the fault plane is not significantly different from that seen on the surface $(H$. Itoh, personal communication). Detailed geodetic surveying also 
Impulse Response

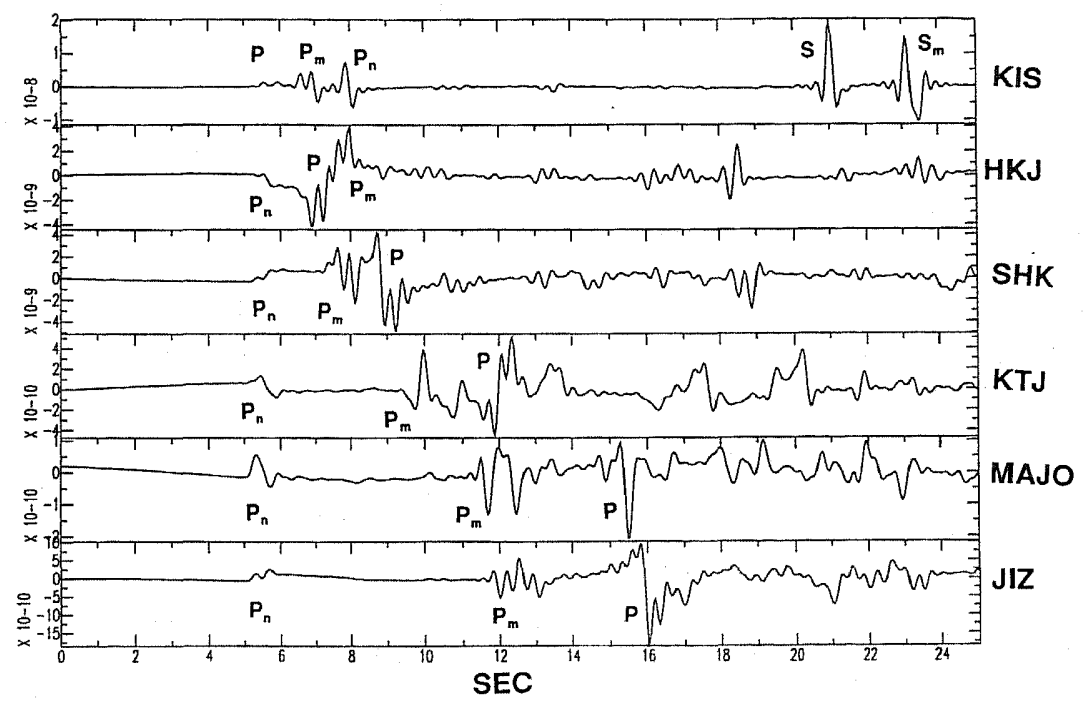

Fig. 6. Synthetic seismograms of vertical component at the stations of Fig. 3. The initial phase is set at $5 \mathrm{~s}$ and the source-time function is impulsive.

confirmed that there are several locations along the Nojima fault where the fault slip is nearly zero, not only near the surface but down to a sufficient depth (M. Hoshino, personal communication). These new results strongly support the theory that surface faultings along the Nojima fault represent the overall character of the entire fault system.

Since the rupture started in Akashi Strait, it is generally believed that the rupture propagated along the Nojima fault from northeast to southwest. The location of the initial rupture area cannot be pin-pointed, particularly the focal depth. Although the initial rupture spread over the fault plane from a focal point at a depth of 10 to $15 \mathrm{~km}$ in a circular manner, the rupture should have propagated mostly in a horizontal direction, rather than bi-dimensionally (i.e., both vertical and horizontal directions), after the rupture front reached the northeastern end of the Nojima fault, about $1 \mathrm{~s}$ after the origin time. In other words, observed waves (Fig. 3) were radiated from not a shallow part of the fault but the entire fault represented by the point source located in the centroid. No clearly concentrated damage has ever been discovered along the Nojima fault in Awaji Island (e.g., Nakata et al., 1995), and we assume the constant rupture velocity although dynamic rupture processes should be studied to reconstruct a more realistic rupture history in the future, including changes in rupture velocity.

The fault motion should continue for more than $3.5 \mathrm{~s}$ along the nearly $9 \mathrm{~km}$-long Nojima fault (Fig. 1), taking the constant rupture velocity to be $2.5 \mathrm{~km} / \mathrm{s}$ as a standard value. The wavefield radiated from slips on a finite fault plane is represented by the integral of dislocations over the fault plane, as a function of time and space (e.g., Aki and Richards, 1980). We obtain synthetic seismograms by multiplying the following factor in frequency domain in order to take into account the first-order directivity effect of the southwestward rupture propagation:

$$
\frac{\sin X}{X} \mathrm{e}^{i X}
$$

and

$$
X=\frac{\omega L}{2}\left[\frac{1}{v}-\frac{\cos \Psi}{c}\right],
$$

where $\omega$ is the angular frequency, $L$ is the fault length, $v$ is the rupture velocity, $c$ is the wave speed (P-wave velocity in the present case), and $\Psi$ is the azimuth of each station with respect to the direction of the rupture propagation. Here we assume that the width of the fault is negligible in comparison with the fault length and that the rupture front 
propagates unilaterally and unidirectionally (BenMenahem, 1961). Since we consider P waves and the azimuthal dependency of $X$ are not as strong as other phases such as $S$ and surface waves, the effect of the above factor is rather minor. This supports our assumption that the finiteness of the fault plane does not strongly affect the broadband data in this study, and that point-source representation is sufficient.

If we consider far-field components only, slips on the fault plane are directly related to the integral of a displacement seismogram (e.g., Aki and Richards, 1980). The integrals of displacement, obtained from the velocity seismograms of Fig. 3, are dominated by low-frequency waves less than $0.3 \mathrm{~Hz}$, and we cannot use them to resolve detailed source processes. We use the velocity seismograms of Fig. 3 for further analyses. Leaving aside how high-frequency waves are radiated from a given slip distribution along a fault trace in future studies, this study uses a point source with the complex source-time function composed of five impulses corresponding to five segments of the slips given in Fig. 1. An impulsive source, whose strength is proportional to the maximum slip in each segment, is put in the center of each segment, and the time interval of the five impulses simulates the rupture-front propagation southwestward along the Nojima fault. Synthetic seismograms at the stations of Fig. 3 in the bottom are shown in Fig. 7 with the assumed source-time function with five impulses in the bottom. In the middle of Fig. 8, the slip distribution observed along the Nojima fault is compared with the adopted source-time function. We set the timing of the first impulse to be delayed by $1 \mathrm{~s}$ from the origin time, simulating the initial rupture extension from the epicenter to the northeastern end of the Nojima fault.

If there were only the direct $\mathrm{P}$-wave and the source were isotropic, seismograms in Fig. 7 would yield five pulses, reflecting the adopted source-time function. Such a waveform of the direct $\mathrm{P}$ wave, however, is not observed in every seismogram. For example, $P_{n}$ and $P_{m}$ phases arrive nearly simultane-

Five pulses

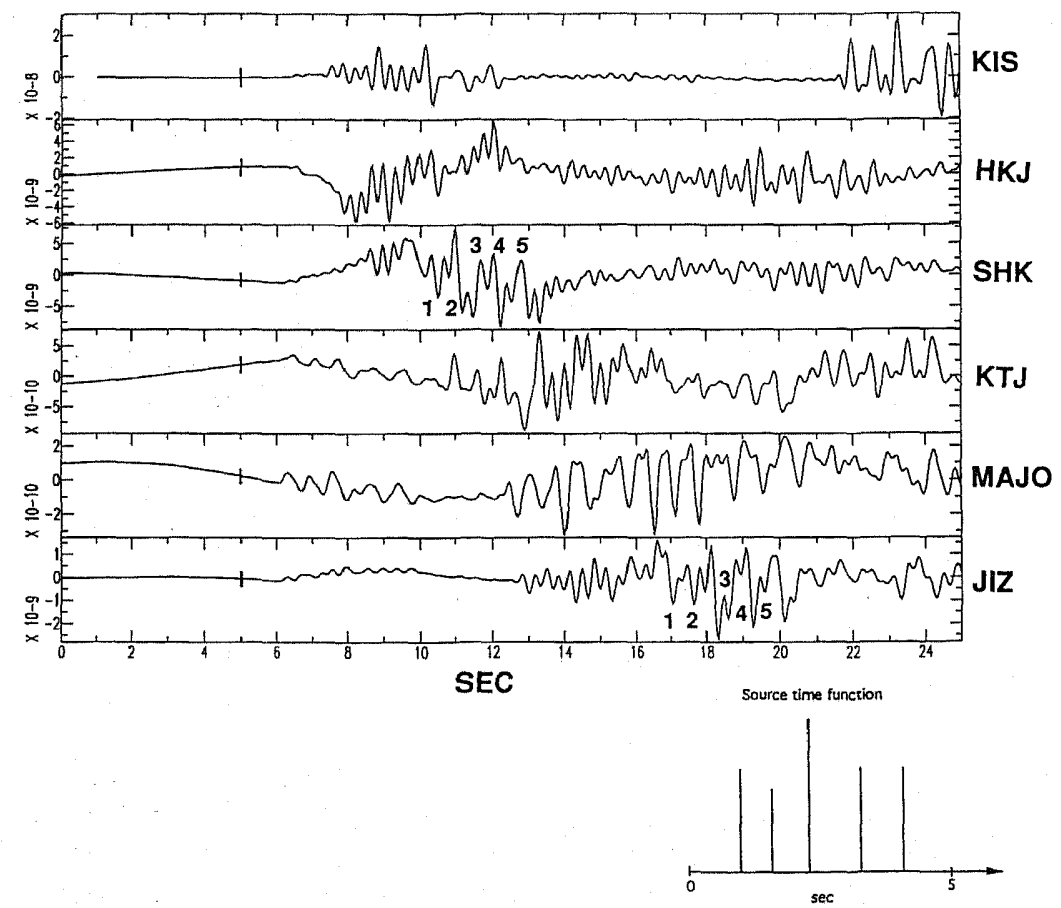

Fig. 7. Same as Fig. 6 except for the source-time function with five pulses to simulate the southwestward rupture propagation along the Nojima fault using the slip distribution of Fig. 1 and correcting the first-order directivity effect for unilateral rupture propagation (Ben-Menahem, 1961). 

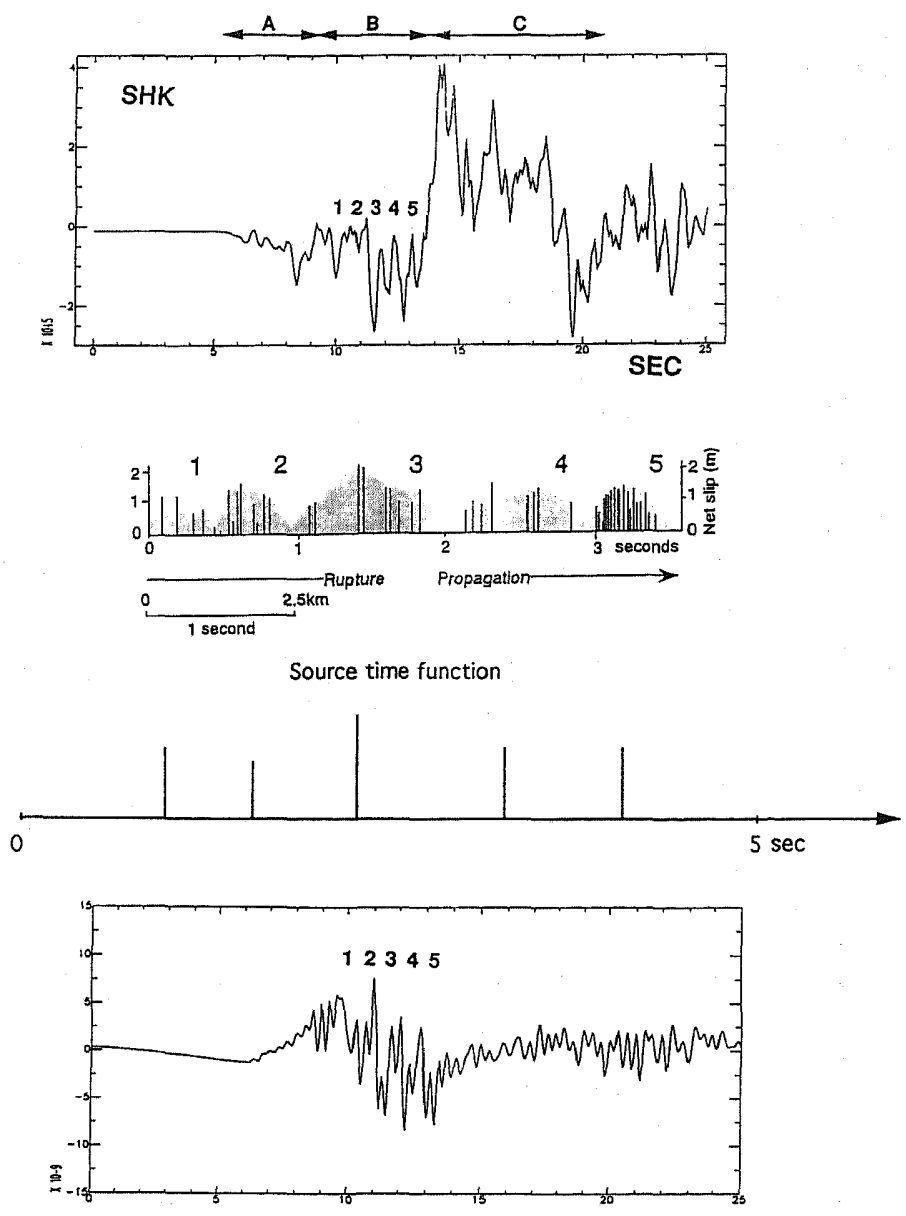

Fig. 8. Broadband vertical seismogram (Fig. 3), net slip distribution along the Nojima fault (Fig. 1), corresponding source-time function, and synthetic seismogram (Fig. 7) at SHK. The source-time function consists of five pulses. The strength of each impulse is proportional to the maximum net slip, and the time interval of the pulses is set to simulate the southwestward rupture propagation along the Nojima fault with the constant rupture velocity of $2.5 \mathrm{~km} / \mathrm{s}$. Note the similarity in part B between the observed and synthetic seismograms, including the arrival time.

ously at $\mathrm{HKJ}$, obscuring the direct $\mathrm{P}$ waveform. At MAJO, the direct $P$ wave is extremely weak, mainly due to the $\mathrm{P}$-wave radiation pattern. As predicted from Fig. 6, seismograms at SHK and JIZ show five pulses relatively clearly, representing details of the source-time function. In the top and bottom of Fig. 8 , the broadband seismogram at SHK is compared with the corresponding synthetic seismogram of Fig. 7. Since the initial phase of the observation is set at $5 \mathrm{~s}$, the start of the synthetic seismogram is set at $6 \mathrm{~s}$, taking into account the time delay of $1 \mathrm{~s}$ for the first impulse of the source-time function. By this comparison, we can discuss the arrival time of each phase in both seismograms directly.

The early phases, named parts $\mathrm{A}$ and $\mathrm{B}$, are simulated successfully by the above procedure. Part A, a weak and smooth start of the seismogram, is attributed to $\mathbf{P}_{\mathrm{n}}$ and $\mathbf{P}_{\mathrm{m}}$ phases or head-wave type phases. Since the synthetic seismograms are computed in the frequency domain first, lowfrequency components of a period of about $5 \mathrm{~s}$ are prominent in the synthetics with the source-time function of the total duration of about $5 \mathrm{~s}$, compared with the data. Part B corresponds to the 
direct $\mathrm{P}$ wave so that it reflects the detailed characteristics of the fault slip along the Nojima fault. As speculated in Yomogida and Nakata (1995), part B of SHK appears to consist of five pulses, suggesting a close relation with the five-segmented slip distribution along the Nojima fault (Fig. 1). The agreement in frequency as high as $2 \mathrm{~Hz}$, as shown in Fig. 8, should not be obtained by chance. By comparison of the observation at JIZ (Fig. 3) with the synthetic seismogram (Fig. 7), the agreement in part $B$ is also proven. While the high-frequency component in data is quite similar to the synthetic seismogram at SHK (Fig. 8), the observed seismogram appears to contain less highfrequency waves than the synthetic seismogram at JIZ. This implies a complex path and attenuation effects even for stations at epicentral distances as large as JIZ, suggesting the importance of near-fault observations in the discussion of fine-scale fault complexities.

Some seismograms (SHK and MAJO) show an additional large phase, named part $\mathrm{C}$, in Fig. 3, which is not included in the present synthetic seismograms. Since we have considered the fault motion only along the Nojima fault, it should come from fault motions in other parts of the fault system. From various kinds of data such as aftershock distribution, it is quite sure that the rupture extended bilaterally from the epicenter in Akashi Strait: southwestward along the Nojima fault and northeastward towards Kobe. Assuming the average rupture velocity to be $2.5 \mathrm{~km} / \mathrm{s}$, the rupture would have extended northeastward by about $10 \mathrm{~km}$ from the epicenter. The large phase of part $\mathrm{C}$ recorded at some seismograms shows the possibility of an additional high-frequency seismic-wave radiation either close the center of Kobe or near the southwestern end of the Nojima fault (Fig. 1). Not only seismic-moment release of relatively low frequencies (e.g., Cho et al., 1995; Kikuchi, 1995) but also geodetic measurements (e.g., Hashimoto et al., 1996) strongly imply much smaller fault slips in the Kobe area than along the Nojima fault. Some geological surveys propose even that there were virtually no slips near the center of Kobe (e.g., Tsukuda, 1996). Some strong-motion studies have also obtained large slip distributions in Awaji Island but very little in the Kobe area although a minor subevent is proposed there (e.g., Sekiguchi et al., 1996). Irikura and Fukushima (1995) found that the spatial attenuation rate of observed peak accelera- tions was not significantly different from other major earthquakes, excluding anomalous high-frequency radiations in the Kobe area. Because such highfrequency radiation has not been observed in the Kobe area, the origin of part $\mathrm{C}$ should not be speculated.

For the first 3 or $4 \mathrm{~s}$ since the origin time, synthetic seismograms obtained from the slips only along the Nojima fault explain part B of the data well, as shown above, and the contribution of the northeastward rupture is not clearly observed. This suggests that the early northeastward rupture propagating across Akashi Strait toward Kobe City might have been so smooth that high-frequency seismic-wave radiations could be neglected. Another possibility is that the fault segmentation in this area was on a scale similar to that of the Nojima fault (Fig. 1), having radiated undistinguishable waveforms in the above synthetic seismograms.

With seismic or geodetic data alone, any deterministic approach will be difficult for source processes involved with high-frequency waves. Field surveys of earthquake faulting have been conducted independently, but their results should be closely correlated with other geophysical observations such as seismic and geodetic data, as proposed by Thatcher and Bonilla (1989). This study presented one of the first attempts to elucidate such a deterministic relation. Applying this approach for future events associated with surface faultings will surely provide useful information on the radiation of high-frequency seismic waves by large earthquakes. The information of surface faultings should be also utilized by other approaches such as in our previous studies on the 1990 Luzon earthquake (Nakata et al., 1990; Yomogida and Nakata, 1994). Meanwhile, we used broadband data with the point-source representation, but near-fault records should be used in the future because the spatial extent of faults is important only for such data.

Broadband seismograms were obtained from the Gopher system of the Earthquake Research Institute, the University of Tokyo, and Takuo Shibutani of the Disaster Prevention Research Institute, Kyoto University. We also thank Kayoko Tsuruga for processing broadband data and Yoko Tono for help with the synthetic seismograms. Ken'ichiro Yamashina and Masayuki Kikuchi pointed out the importance of $P_{n}$ for the interpretation of broadband data. Haruko Sekiguchi kindly informed the results of her paper prior to its publication. Comments by 
two anonymous reviewers and the editors are greatly appreciated.

\section{REFERENCES}

Aki, K. and P. G. Richards, Quantitative Seismology: Theory and Methods, W. H. Freeman, San Francisco, 932 pp., 1980.

Ben-Menahem, A., Radiation of seismic surface waves from finite moving sources, Bull. Seismol. Soc. Am., 51, $401-435,1961$.

Cho, I., I. Nakanishi, and K. Kanjo, The source mechanism of the Hyogoken-nambu earthquake of January 16, 1995, J. Nat. Disast. Sci., 16, 21-29, 1995.

D.P.R.I. R.C.E.P., Preliminary report on the January 17, Hyogoken-nambu earthquake, Rep. Coord. Comm. Earthq. Predict., 113, 1-22, 1995 (in Japanese).

Grand, S. and D.V. Helmberger, Upper mantle shear structure of North America, Geophys. J. R. Astron. Soc., 76, 399-438, 1984.

Hashimoto, M., T. Sagiya, H. Tsuji, Y. Hatanaka, and T. Tada, Coseismic displacements of the 1995 Hyogo-ken Nanbu earthquake, J. Phys. Earth, 44, 255-279, 1996.

Helmberger, D. V., Theory and application of synthetic seismograms, in Earthquakes: Observation Theory and Interpretation, ed. H. Kanamori and E. Boschi, Soc. Italiana di Fisica, Bologna, pp. 174-222, 1983.

Irikura, K. and Y. Fukushima, Attenuation characteristics of peak amplitude in the Hyogoken-nambu earthquake, J. Nat. Disast. Sci., 16, 39-46, 1995.

Iwata, T., K. Hatayama, H. Kawase, K. Irikura, and K. Matsunami, Array observation of aftershocks of the 1995 Hyogoken-nambu earthquake at Higashinada Ward, Kobe City, J. Nat. Disast. Sci., 16, 41-48, 1995.

Kamae, K. and K. Irikura, A fault rupture model of the 1995 Hyogoken-nambu earthquake $\left(M_{\mathrm{JMA}}=7.2\right)$ estimated by empirical Green's function method, J. Nat. Disast. Sci., 16, 31-40, 1995.

Kennett, B. L. N., Systematic approximations to the seismic wavefield, in Seismological Algorithm, ed. D. J. Doornbos, Academic Press, London, pp. 237-259, 1988.
Kikuchi, M., The mechanism of the Hyogo-ken Nanbu earthquake of January 17, 1995, Yokohama City College Seismol. Rep., 38, 1995.

Matsumoto, N., K. Yomogida, and S. Honda, Fractal analysis of fault systems in Japan and the Philippines, Geophys. Res. Lett., 19, 357-360, 1992.

Nakata, T. and K. Yomogida, Surface fault characteristics of the 1995 Hyogoken-Nambu earthquake, J. Nat. Disast. Sci., 16, 1-9, 1995.

Nakata, T., H. Tsutsumi, R. S. Punongbayan, R. E. Rimando, J. Daligdig, and A. Daag, Surface faulting associated with the Philippine Earthquake of 1990, J. Geogr., 99, 95-112, 1990 (in Japanese).

Nakata, T., K. Yomogida, J. Odaka, T. Sakamoto, K. Asahi, and N. Chida, Surface fault ruptures associated with the 1995 Hyogoken-Nanbu earthquake, J. Geogr., 104, 127-142, 1995 (in Japanese).

Okubo, P.G. and K. Aki, Fractal geometry in the San Andreas fault system, J. Geophys. Res., 92, 345-355, 1984.

Sekiguchi, H., K. Irikura, T. Iwata, Y. Kakehi, and M. Hoshiba, Determination of the location of faulting beneath Kobe during the 1995 Hyogo-ken Nanbu, Japan, earthquake from near-source particle motion, Geophys. Res. Lett., 23, 387-390, 1996.

Thatcher, W. and M. G. Bonilla, Earthquake fault slip estimation from geologic, geodetic and seismologic observations: implications for earthquake mechanics and fault segmentation, U.S. Geol. Serv. Open File Rep., 89-313, 386-399, 1989.

Tsukuda, E., Active tectonics and intraplate paleoseismic activities, southwest Japan, Bull. Geol. Surv. Jpn., 47, 57-94, 1996.

Yomogida, K. and T. Nakata, Large slip velocity of surface rupture associated with the 1990 Luzon earthquake, Geophys. Res. Lett., 21, 1799-1802, 1994.

Yomogida, K. and T. Nakata, Relation between seismic observations and the fault complexity of the 1995 Hyogoken-nambu earthquake, J. Nat. Disast. Sci., 16, 11-19, 1995. 